\title{
62 anos de inclusão do deficiente visual
}

Resumo: No ano das comemorações mundiais dos 200 anos do nascimento do criador do sistema braille de leitura e escrita, a presidente emérita e vitalícia da Fundação Dorina Nowill para Cegos, há mais de sessenta anos trabalhando para a inclusão social do deficiente visual no Brasil e eleita, no ano passado, pela revista Forbes uma das cinco mulheres mais influentes do País, conta um pouco de sua vida neste Depoimento para a revista Comunicação \& Educação. A Fundação Dorina Nowill para Cegos possui a maior imprensa braille do Brasil. Produz livros de literatura, didáticos, partituras de música, entre outros. Em 2007, atingiu a impressionante marca de mais de 33 milhões de páginas impressas em braille. Os livros editados pela entidade são distribuídos gratuitamente para deficientes visuais e mais de 1.650 organizações, como escolas, universidades e associações.

Palavras-chave: Fundação Dorina Nowill para Cegos, Sistema braille, inclusão social.
Abstract: In the occasion of 200 years world commemoration of the Braille system creator birth, the emeritus and lifelong president of Fundação Dorina Nowill para Cegos, who has worked for more than 60 years for the social inclusion of the visually impaired individuals in Brazil and elected last year by Forbes Magazine as one of the most influent women in this country, tells us about her life in this testimonial for revista Comunicação \& Educação. Fundação Dorina Nowill para Cegos is the major publisher of Braille books in Brazil. It produces books on Literature, Textbooks, Music Scores, among other materials. In 2007, it reached the impressive production of 33 million pages of Braille. Books published by that organization are freely distributed for visually impaired individuals and more than 1.650 organizations, such as schools, universities, and associations.

Keywords: Fundação Dorina Nowill para Cegos, braille system, social inclusion.

A Comissão Brasileira para o Bicentenário de Louis Braille realizará eventos para celebrar os 200 anos do nascimento do criador do sistema braille de leitura e escrita. O sistema deu às pessoas cegas acesso ao conhecimento científico, literário, filosófico, tecnológico e, acima de tudo, à inclusão na sociedade. A comemoração dessa data é incentivada pela União Mundial dos Cegos (UMC), que atua junto às agências da Organização das Nações Unidas (ONU) para assuntos relacionados à cegueira. A UMC representa mais de 180 milhões de pessoas e 600 organizações distribuídas em 158 países. No Brasil, os eventos serão comandados pela União Brasileira de Cegos (UBC), que instituiu a Comissão Brasileira para o Bicentenário de Louis Braille (CBBLB), integrada por um grupo de pessoas envolvidas com as diversas áreas de aplicação do sistema braille. A comissão tem como presidente de honra Dorina de Gouvêa Nowill, presidente emérita e vitalícia da Fundação Dorina Nowill para Cegos ${ }^{1}$, que trabalha há mais de sessenta anos na inclusão social do deficiente visual no Brasil. A Fundação possui a maior imprensa braille brasileira, onde são produzidos livros de literatura, didáticos, partituras, entre outros. Em 2007, atingiu

Recebido: 03.10.2008

Aprovado: 06.10.2008

1. Disponível em: <http:// www.fundacaodorina.org. br>. 
comunicação \& educação • Ano XIV • Número 1 • jan/abr 2009

a impressionante marca de mais de 33 milhões de páginas impressas em braille. Os livros editados pela entidade são distribuídos gratuitamente para deficientes visuais e mais de 1.650 organizações, como escolas, universidades e associações. Dorina Nowill, eleita no ano passado, pela revista Forbes, uma das cinco mulheres mais influentes do País, conta um pouco de sua vida neste Depoimento para a revista Comunicação \& Educação.

Nasci em São Paulo, em 1919. Sou filha de pai português e mãe italiana. Tive uma infância muito feliz. Éramos uma típica família de classe média. Em casa reinaram a disciplina e a obediência que, embora muito severas, não eram propriamente impostas, fluíam naturalmente. Eu e meu irmão fomos criados com muito carinho por nossos pais. Sempre fui bastante religiosa e sempre aceitei minha fé sem muitas discussões nem problemas. Fato que exerceu profunda influência em várias fases, quando tive de enfrentar sérias dificuldades.

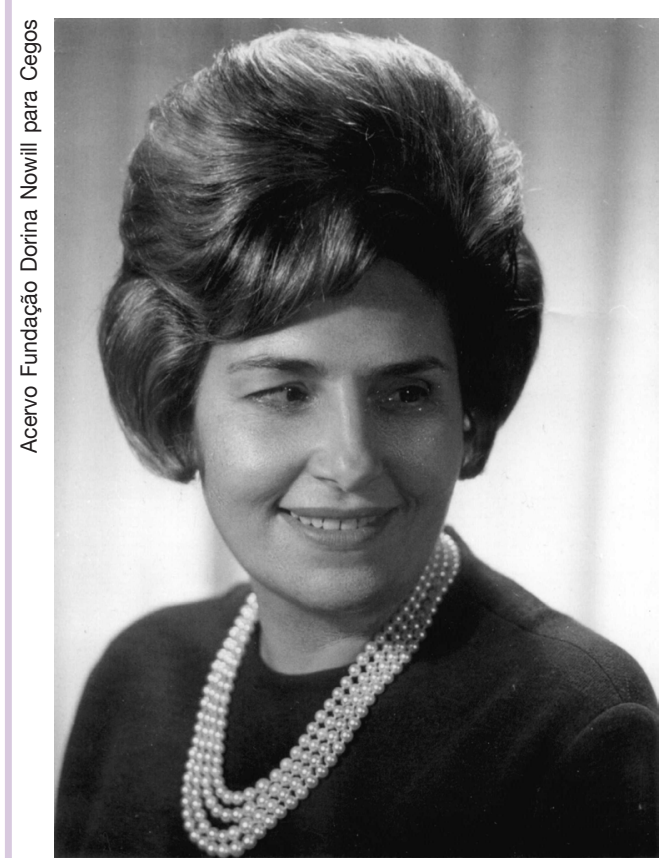

Dorina Nowill quando jovem.

Aos 17 anos, devido a uma patologia ocular, fiquei cega. Decidi continuar meus estudos. Entretanto, naquela época, os estudantes deficientes visuais tinham pouco acesso à cultura e à informação, devido à falta de livros. Por esta razão, em 1946, eu e um grupo de amigas criamos a Fundação para o Livro do Cego no Brasil, organização que, em 1991, recebeu meu nome em reconhecimento do trabalho realizado ao longo dos anos. Fui a primeira aluna cega a matricular-se, em São Paulo, numa escola comum de formação de professores.

Ainda estudante, consegui que a Escola Caetano de Campos implantasse o primeiro curso de especialização de professores para o Ensino de Cegos, em 1945.

As primeiras atividades da antiga Fundação para o Livro do Cego no Brasil foram destinadas exclusivamente a suprir as necessidades de livros em braille para estudantes e outras pessoas cegas. Essas atividades, que inicialmente tiveram o apoio da Cruz Vermelha Brasileira, eram realizadas por um Grupo de Voluntários que transcreviam os livros em braille por processo manual. Os alunos do Curso de Especialização de Professores para Cegos da Escola Caetano de Campos, liderados por mim, treinavam os voluntários para esse trabalho. Essa foi a semente que culminou na criação da Fundação, com atividades funcionando em sala cedida pela Cruz Vermelha. 
Após me diplomar, viajei para os Estados Unidos da América, com uma bolsa de estudos patrocinada pelo governo americano, pela Fundação Americana para Cegos e pelo Instituto Internacional de Educação, para frequentar um curso de especialização na área de deficiência visual na Universidade de Columbia. Retornando ao Brasil, dediquei-me ao trabalho pioneiro da Fundação: a implantação da primeira imprensa braille de grande porte no país, e fui responsável pela criação, na Secretaria da Educação de São Paulo, do Departamento de Educação Especial [...]. Nesse empenho, a educação para cegos se transformou em atribuição do Governo quando, em 1953, em São Paulo, e em 1961, na Capital Federal, o direito à educação ao cego foi regulamentado em lei. No período de 1961 a 1973, dirigi o primeiro órgão nacional de educação de cegos no Brasil, criado pelo Ministério da Educação, Cultura e Desportos. Realizei programas e projetos que implantaram serviços para cegos em diversos estados do país, assim como eventos e campanhas para a prevenção da cegueira.

\section{A FUNDAÇÃO DORINA NOWILL PARA CEGOS}

Sou presidente da Fundação Dorina Nowill para Cegos desde 1951, e recebi o título de presidente emérita e vitalícia. Há mais de seis décadas a fundação tem-se dedicado à inclusão social das pessoas com deficiência visual, por meio da educação e cultura, atuando na produção de livros em braille, livros e revistas falados e obras acadêmicas no formato digital acessível, distribuídos gratuitamente para pessoas com deficiência visual e para centenas de escolas, bibliotecas e organizações de todo o Brasil.

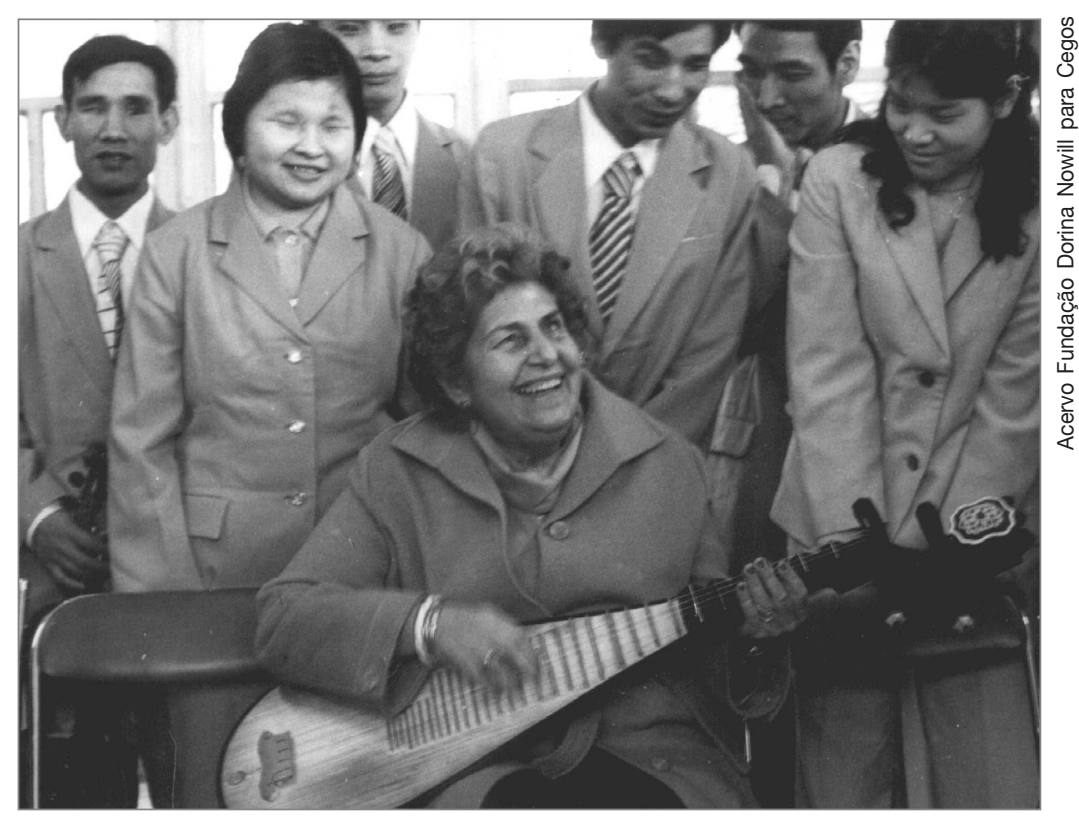

Música, atividade natural de integração. 
A Fundação também oferece, gratuitamente, programas de atendimento especializado ao deficiente visual e sua família, nas áreas de avaliação e diagnóstico, educação especial, reabilitação e colocação profissional.

Acreditamos que a educação seja o melhor caminho para a inclusão social, e ampliar essa oportunidade a milhares de deficientes visuais de todo o Brasil também depende de todos vocês.

Para a pessoa com deficiência visual, ter o acesso garantido à literatura, ao estudo ou ao entretenimento é questão primordial para seu desenvolvimento pessoal. [...] Anualmente são produzidas milhares de páginas em braille de livros didático-pedagógicos, paradidáticos, literários e obras específicas solicitadas pelos deficientes visuais. Somos a imprensa braille com a maior produção da América Latina e uma das referências mundiais em qualidade e complexidade de produção.

Estudantes cegos de todo o Brasil estudam com os livros produzidos na Fundação; um mérito para todos os nossos funcionários envolvidos na produção destes produtos. Produzimos ainda revistas Veja e Cláudia, além de outras publicações específicas sob demanda. A Biblioteca Circulante de Livro Falado da Fundação Dorina Nowill para Cegos possui um acervo com mais de 900 títulos em áudio de obras de diversos autores, desde clássicos da literatura brasileira aos mais variados best-sellers internacionais. Esse serviço está disponível gratuitamente às pessoas com deficiência visual de todo o Brasil. Voltado para universitários e profissionais liberais deficientes visuais, o LIDA - Livro Digital Acessível, permite acesso amplo, rápido e estruturado à literatura destinada ao estudo e à pesquisa. Além do texto em áudio, o usuário com visão subnormal pode visualizar o conteúdo em até cinco níveis de ampliação de tela. A ferramenta possui tutorial e mecanismos de busca por palavras ou frase, notas de rodapé opcionais, marcadores de texto, soletração, leitura integral de abreviaturas e sinais, além da pronúncia correta de palavras estrangeiras, entre outras funcionalidades. Inicialmente, estão disponíveis obras nas áreas de Direito, Psicologia, Pedagogia, Filosofia, obras de referência e dicionários como Michaelis e Aurélio.

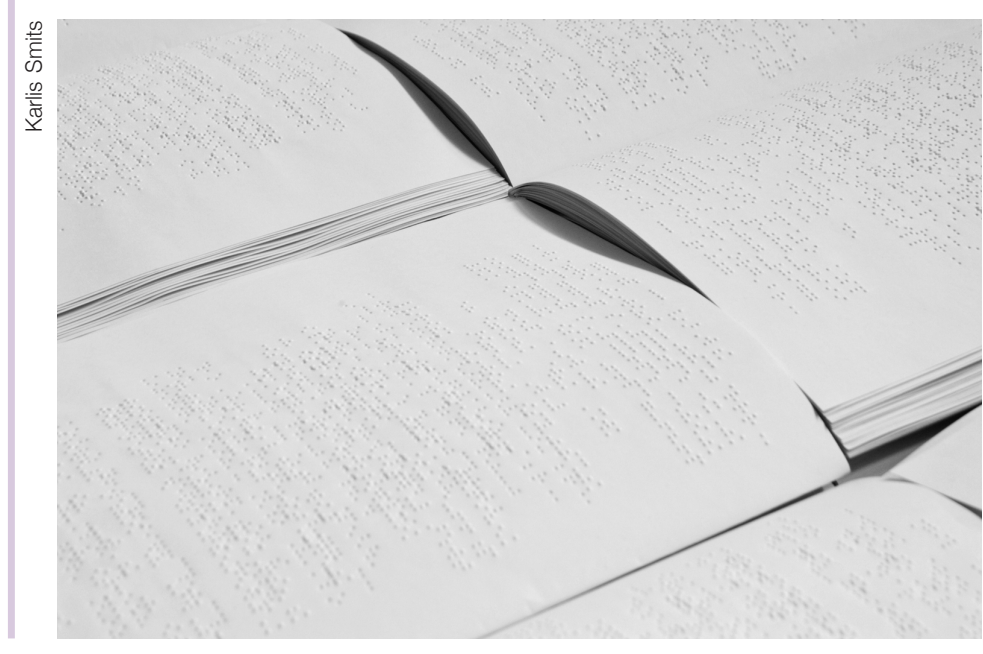

Páginas impressas em braille. 
Essa convivência com a realidade nos possibilitou realizar também a prestação de serviços na área de consultoria e impressão braille de produtos como: manuais, relatórios, cardápios, calendários, cartões de visita, catálogos e outros. Além de desenvolver projetos especiais impressos no sistema braille e nos formatos áudio e digital acessível.

\section{EDUCAÇÃO, INCLUSÃO SOCIAL E AS NOVAS TECNOLOGIAS}

Em 62 anos, muitas transformações aconteceram no mundo em relação às pessoas cegas, às condições sociais e à própria cegueira. A deficiência visual é um fato que pode acontecer na vida de qualquer um e produz nas pessoas comportamentos e atitudes que diferem de pessoa para pessoa, mas acima de tudo se reconhece que o indivíduo cego ou com baixa visão é um ser humano igual aos outros em sua essência, inclusive com os mesmos deveres e direitos.

A evolução dos processos de saúde, da educação e da tecnologia trouxe modificações na maneira de se avaliar e atender as pessoas com deficiência visual. No Brasil é preciso reconhecer que soluções foram apontadas e, no decorrer dos anos, muitos aspectos do atendimento especializado a elas contribuíram para a melhoria das suas condições de vida e, de certa forma, modificaram a sua participação na vida cotidiana.

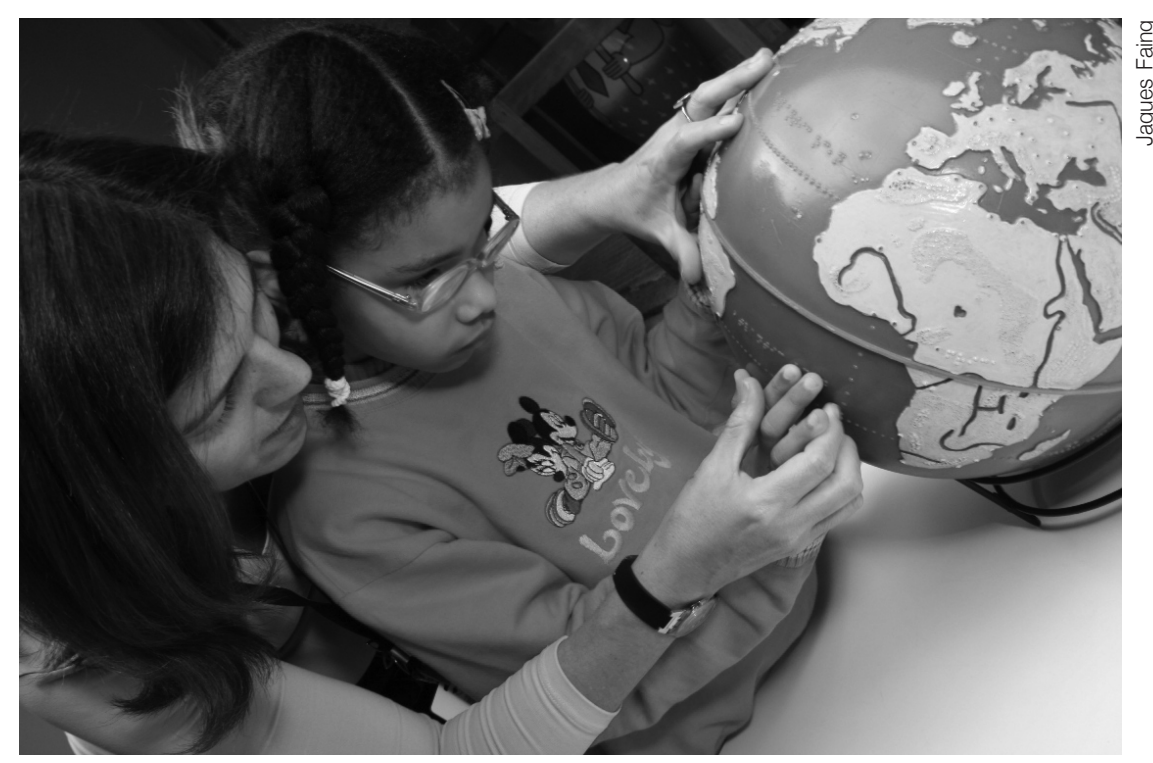

Atendimento à criança deficiente visual.

As novas tecnologias abriram acessos favoráveis à inclusão das pessoas com deficiência na vida comunitária, favorecendo uma adequada atitude em relação ao exercício da própria cidadania. Pode-se dizer, porém, que um dos maiores obstáculos está diretamente ligado à mobilidade, acrescida 
de outras dificuldades, como a perda do emprego, problemas financeiros, ausência de legislação adequada.

A Constituição Brasileira diz que "a educação é um direito de todos", o que é reforçado nos textos das políticas públicas. Porém, se considerarmos os dados estatísticos disponíveis sobre o número de pessoas com deficiência visual, é fácil concluir que muitas não têm as mesmas oportunidades de acesso a esse bem, devido a fatores diversos como recursos financeiros, número de profissionais especializados e outros. A cada país cabe a tarefa de planejar e propor programas de âmbito federal, estadual e municipal que supram as deficiências existentes e contribuam para que a maioria das pessoas com deficiência visual possa ser atendida em suas necessidades específicas e usufruir dos direitos de verdadeiros cidadãos.

A sociedade civil está cada vez mais organizada. O chamado terceiro setor é uma prova disso. É ele que, em matéria de serviços, desenvolve muito mais ações do que as próprias instituições públicas; e que também cobre boa parte das carências do nosso país.

A inclusão nada mais é do que a aplicação da lei que garante direitos e deveres iguais para todos. No caso dos deficientes, a legislação não é

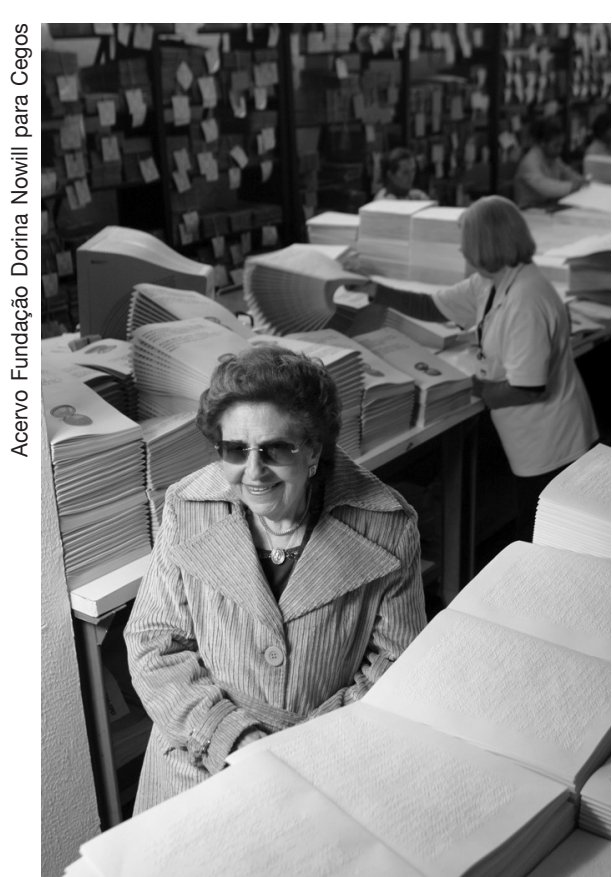

Dorina Nowill entre algumas publicações em braille. perfeita, mas tenta obrigar a sociedade civil a cumprir a sua parte no mecanismo da cidadania. Um exemplo disso é a lei que determina às empresas preencherem uma porcentagem do seu quadro de funcionários [...] com deficientes. Essa ainda não é a solução, mas trata-se de um começo. Para garantir direitos e deveres iguais, é preciso oferecer à pessoa com deficiência oportunidades iguais. É essencial que ela possa desenvolver suas aptidões e ser reconhecida naquilo que é capaz de fazer. Não basta dar emprego, é necessário que o deficiente esteja apto a executar as suas tarefas e a progredir profissional, social e economicamente, como todos os outros cidadãos.

A educação inclusiva evoluiu muito nos últimos anos, mas se você observá-la como estrutura, verá que há grandes falhas ainda. A especialização do professor que trabalha com alunos deficientes ainda é muito precária. De fato, a educação por si só já é bastante falha, mas, no caso da educação especial, essa fragilidade se torna mais evidente. No lado do estudante, verificamos que a formação do deficiente é muito escassa. Falta material didático e acesso a outros meios de educação, que não são limitados apenas 
às escolas. Além do que, é preciso que o educador saiba que na sua classe há pessoas deficientes e que elas necessitam de diferentes estímulos. Vale lembrar que inclusão é tudo. Deve acontecer no comércio, na indústria, nos meios de locomoção. Tudo isso tem de ser repensado para que o deficiente tenha uma participação mais ativa no mundo em que vive. Acima de tudo, a inclusão tem que começar na própria família.

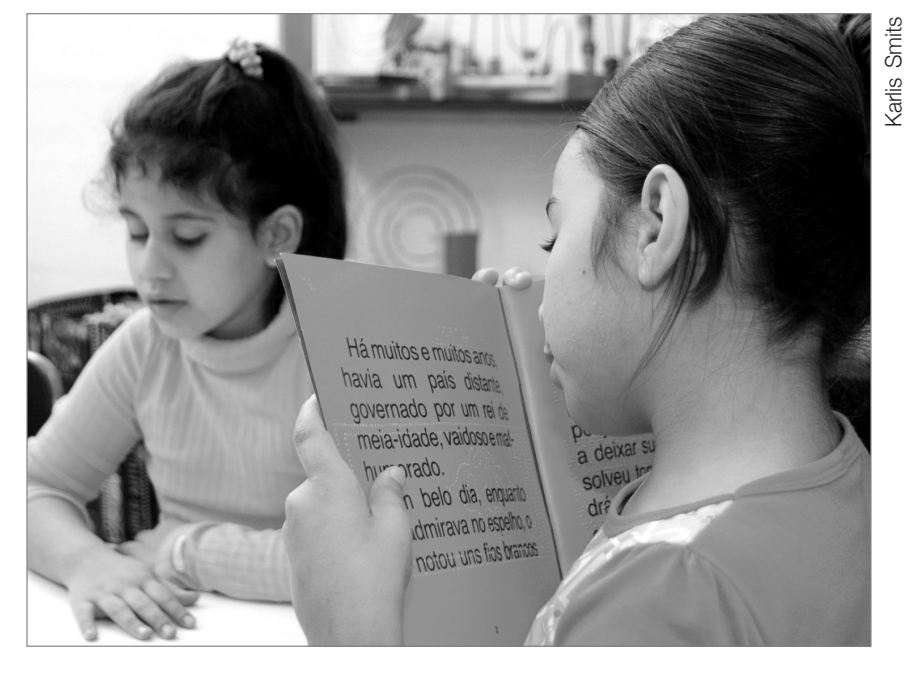

Os deficientes visuais têm acesso à literatura.

\section{RECONHECIMENTO}

Em nível internacional, trabalhei com organizações mundiais de cegos e órgãos da ONU, como representante do Brasil. Ocupei importantes cargos em Organizações Internacionais de Cegos. Em 1979, fui eleita presidente do Conselho Mundial dos Cegos. Em 1981, Ano Internacional da Pessoa Deficiente, falei na Assembleia Geral da ONU. Também trabalhei intensamente para a criação da União Latino-Americana de Cegos - ULAC.

Em 1989, outra vitória: o Congresso Nacional ratificou a Convenção 1599 da OIT, que trata da reabilitação, do treinamento e da profissionalização de cegos; resultado de mais uma luta que havia começado dezoito anos antes, com o primeiro centro de reabilitação criado pela Fundação.

O Centro de Memória Dorina Nowill, que reúne a história da Fundação e parte da história de luta pela inclusão social, foi um dos 20 selecionados no concurso Prêmio Darcy Ribeiro 2008, cujo objetivo era condecorar as melhores ações e práticas promovidas pelos museus na área educativa. $\mathrm{O}$ projeto fará parte, junto aos demais ganhadores, de uma publicação sobre experiências e ações educativas em museus, a ser materializada e distribuída nacionalmente pelo Departamento de Museus e Centros Culturais do IPHAN. O Centro de Memória Dorina Nowill tem uma exposição aberta ao público que segue os critérios de acessibilidade, orienta museus a receberem pessoas com deficiência visual, mantém um grupo de avaliação de acessi- 
comunicação \& educação • Ano XIV • Número 1 • jan/abr 2009

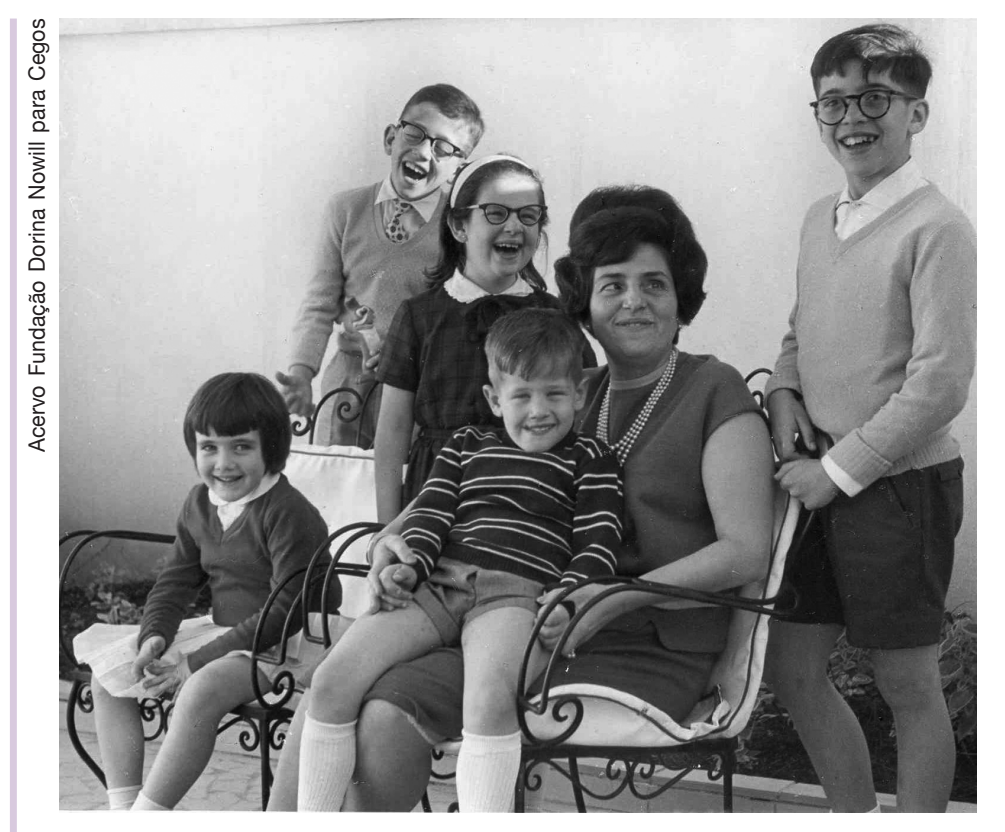

Dorina e os cinco filhos.

bilidade em museus composto por pessoas com deficiência visual e, desde 2006, promove o programa de formação em acessibilidade para museus.

Em 2004, Maurício de Sousa, numa homenagem querida a mim e ao nosso trabalho na fundação, criou a personagem Dorinha, como um símbolo para a conscientização das crianças quanto à questão da deficiência visual.

O reconhecimento mundial da nossa atuação em prol do desenvolvimento e da inclusão social de pessoas com deficiência visual é concretizado por meio de inúmeros prêmios, condecorações, títulos, comendas e outras recompensas concedidas por organizações do mundo todo, pelo governo brasileiro e por organizações brasileiras.

Em 1996 publiquei minha autobiografia, intitulada “... E eu venci assim mesmo".

Atualmente me dedico a divulgar a Fundação Dorina e seu trabalho.

Sou mulher, cidadã, esposa, dona de casa, mãe de cinco filhos e avó de 12 netos.

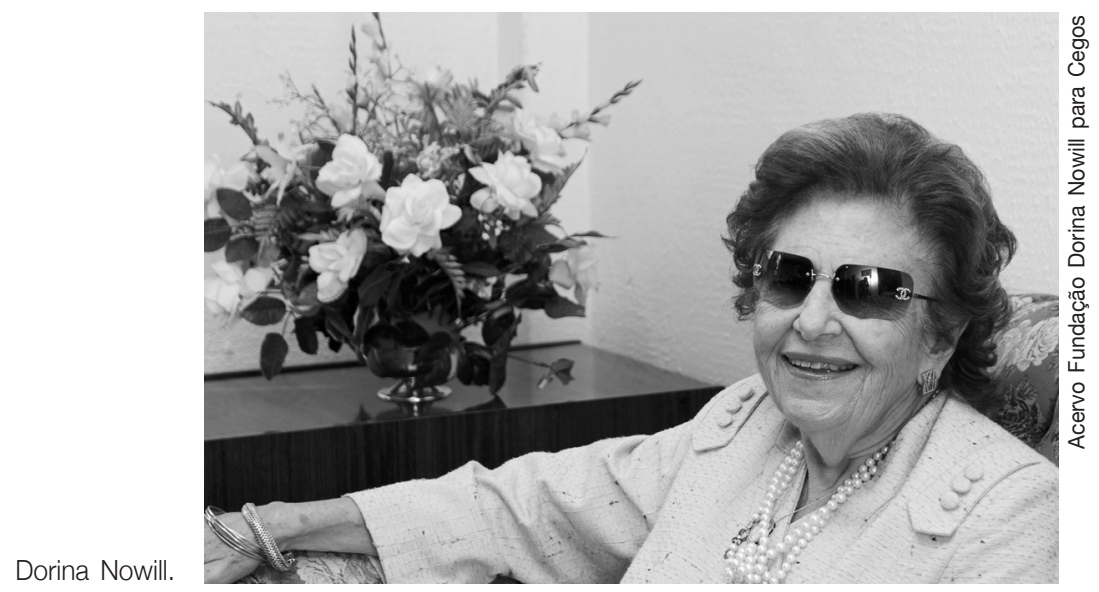

